\title{
Effectiveness of Functional Electrical Stimulation - Cycling Treatment in Children with Cerebral Palsy
}

\author{
Natalya Özen, Ece Unlu, Ozgur Zeliha Karaahmet, Eda Gurcay, Ibrahim Gundogdu, Ebru Umay
}

Department of Physical Medicine and Rehabilitation, Diskapi Yildirim Beyazit Education and Research Hospital, Ankara Turkey

Correspondence: Natalya Özen (kuzovichnatalya@hotmail.com)

\begin{abstract}
Aim
Abstract

The purpose of this study was to evaluate the effects of functional electrical stimulation (FES) bicycle therapy system on motor function, gait pattern, spasticity, daily living activities, and aerobic capacity in children with cerebral palsy (CP) and to compare the results with sham stimulation and standard treatment.

Methods

Patients with cerebral palsy who received botulinum toxin type-A injections to lower extremities and those with Gross Motor Function Measure Classification System (GMFCS) levels I - III, were included in the study. Twenty-five patients were randomly assigned into three treatment groups for 4-weeks: Group 1, FES-cycling and standard treatment; Group 2, Sham stimulus FES-cycling and standard treatment; Group 3, Standard treatment. Clinical assessment tools included the Modified Ashworth Scale (MAS), Modified Tardieu Scale (MTS), Pediatric Functional Independence Measure (WeeFIM), GMFCS, Gross Motor Function Measure-88 (GMFM-88), selective motor control tests, 6-minute walk test, and Visual Gait Analysis (VGA).

Results

In all groups, there were significant improvements in MAS, MTS, WeeFIM, GMFM-88, 6-minute walk test, and VGA scores. No changes in GMFCS levels were observed in any group. At the end of the study, there was no significant difference among the groups in terms of any clinical assessment parameter.

Conclusions

All groups showed statistically significant improvements in motor function, walking pattern, spasticity, daily living activities, and aerobic capacity in patients with CP following the rehabilitation period. Although FES-cycling demonstrated no superiority over the other approaches and provided no additional benefit to the results, FES appears to be safe and well-tolerated in children with CP, at least as much as standard exercise treatment.
\end{abstract}

Keywords: Bicycle ergometry, botulinum toxin, cerebral palsy, functional electrical stimulation

\section{Introduction}

Cerebral palsy (CP), one of the most frequent causes of childhood disability, is a nonprogressive motor dysfunction that affects muscle tone, posture, and movement. Although the disorder itself is not progressive, the clinical expression may change over time as the musculoskeletal and the central nervous system matures. The motor impairment generally results in limitations in functional abilities and activity ${ }^{1}$. One of the aims of the $\mathrm{CP}$ treatment is to increase their functional capacity as much as possible ${ }^{2}$. Although Rehabilitation of CP has performed by rehabilitation professionals for a long time, many new treatment methods have emerged in recent years. Although Botulinum toxin is a commonly used and effective treatment method for reducing spasticity in $\mathrm{CP}$, it is not a single-handed practice, but rather one part of a multi-faceted rehabilitation program. The reduction in spasticity after botulinum toxin injections provides a therapeutic window

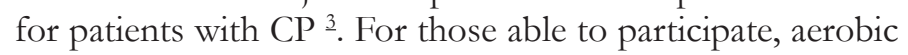
exercises decrease the energy consumption for ambulation and increase muscle strength, gross motor function, and for those able to use such equipment motivation, ultimately helping people feel better ${ }^{4}$. Such exercises include voluntary and coordinated movements that are repetitive and reciprocal 5. Equipment such as treadmill, bicycle (for those able to use such equipment), and upper limb ergometer is therefore used and increase the aerobic capacity of the whole body and local muscles ${ }^{6}$. Cycling is an exercise that challenges the muscular and cardiovascular systems and potentially leads to improved health, fitness, and well-being. Cycling with functional electrical stimulation (FES) has been used primarily for people with spinal cord injury; improvements in bone mineral density, muscle strength (force-generating capacity), and cardiorespiratory measures were observed 7. FES-cycling is a relatively new technology, and very few studies have been conducted on the effect of this method in children with $\mathrm{CP} \frac{8,9,10}{\text {. }}$.

The present study aimed to evaluate the effects of FEScycling therapy on motor function, walking pattern, spasticity, daily living activities, and aerobic capacity in patients with CP.

\section{Methods}

\section{Participants}

The present study included patients who were between 4 to 12 years old, diagnosed with diplegic CP, and GMFCS levels I to III, and received botulinum toxin type-A injections to the hamstring and gastrocnemius muscle groups every 6-9 months as needed. The approval of the study protocol was obtained from the local ethics committee of the University of Health Sciences, Dışkapı Yıldırım Beyazıt Training and Research Hospital, and written informed consent was obtained from the parents of the children. The study was conducted by the principles of the Declaration of Helsinki ${ }^{11}$. 
Children who had limited ability to cooperate, diagnoses of athetoid or ataxic CP, undergone orthopedic surgery, vasomotor instability (coagulation disorder), lower motor neuron disorder, limitation/instability/dislocation of the hip-knee joints, severe spasticity (Modified Ashworth Scale $(\mathrm{MAS})>3$ ), pressure ulcer/skin loss in the area of a stimulation point, or uncontrolled epilepsy were excluded from the study.

The demographic and clinical characteristics of the patients were recorded. Patients were divided into 3 groups and randomized by sealed envelope method $\frac{12}{\text {; }}$ Group $1(\mathrm{n}=9)$ comprised patients receiving FES-cycling and standard treatment; Group $2(\mathrm{n}=9)$ comprised patients with sham stimulus FES-cycling and standard treatment; Group 3 $(\mathrm{n}=7)$ comprised patients receiving standard treatment alone. Numbers 1, 2 and 3 were written inside the envelopes for three groups and were prepared $9 \times 3=27$ of these envelopes. Two patients in the group with standart treatment dropped out of the study due to medical problems. As a result of it the study was finished with 7 patients in one group and 9 patients in two other groups.

\section{Outcome Measures}

Ankle and knee flexor spasticity was assessed using the Modified Ashworth Scale (MAS) and the Modified Tardieu Scale (MTS) 13,14 . All of the measurements were taken in the supine position, the head position was in midline and the resting limb position was neutral. The scores for MAS were determined according to the level of resistance during the passive movement of the antagonist muscles. MTS was measured at 2 different velocities; XV1- slow as possible, slower than the gravitation force and natural fall, XV3moving as fast as possible, faster than the gravitation force and natural fall.

In the evaluation of motor and functional status, Pediatric Functional Independence Measure (WeeFIM), Gross Motor Function Classification System (GMFCS) $\frac{15}{5}$, Gross Motor Function Measure-88 (GMFM-88) $\frac{15,16}{16}$, visual gait analysis, and selective motor control (SMC) tests ${ }^{17}$ were used.

Pediatric Functional Independence Measure (WeeFIM) was also used for daily living activities evaluation $\frac{18}{}$.

Selective motor control was performed to evaluate the voluntary motor control of the ankle dorsiflexor muscles. The examiner first demonstrates the task by passively moving the limb, then the patient who was in the supine position, was asked to bring the ankle to dorsiflexion. It was scored from 0 to 4 (0: no active movement, 1: limited dorsiflexion, 2: dorsiflexion using extensor hallucis longus and extensor digitorim longus activity, 3: dorsiflexion accompanied by hip and/or knee flexion, 4: selective dorsiflexion of the ankle).

The visual gait analysis was performed to all patients by video recording and used the anterior, posterior, and lateral planes. During the video recording the children were walking barefoot or with orthoses at a self-selected speed along a $10 \mathrm{~m}$ walkway. The visual gait analysis results were recorded according to the hip, knee, and ankle joint positions during walking using the Physician Rating Scale (PRS) (Table 1$)^{10}$.

The 6-minute walk, test was performed to assess aerobic capacity ${ }^{20}$. Before the test all the children were explained the rules of the test. For the test, it was used a $10 \mathrm{~m}$ straight corridor, with a flat hard surface, free of obstacles. The distance covered by a child was recorded by a physiatrist. .11
Table 1: Visual Gait Analysis

\begin{tabular}{|c|c|c|}
\hline Definition & Right & Left \\
\hline \multicolumn{3}{|l|}{ Crouch } \\
\hline Severe (>20 hip, knee, ankle) & 0 & 0 \\
\hline $\begin{array}{l}\text { Moderate (5-20 hip, knee, } \\
\text { ankle) }\end{array}$ & 1 & 1 \\
\hline Mild $\left(<5^{\circ}\right.$ hip, knee, ankle) & 2 & 2 \\
\hline None & 3 & 3 \\
\hline \multicolumn{3}{|l|}{ Knee } \\
\hline Recurvatum $>5^{\circ}$ & 0 & 0 \\
\hline Recurvatum $0-5^{\circ}$ & 1 & 1 \\
\hline Neutral & 2 & 2 \\
\hline \multicolumn{3}{|l|}{ Foot contact } \\
\hline Toe & 0 & 0 \\
\hline Toe-heel & 1 & 1 \\
\hline Flat & 2 & 2 \\
\hline Occasional heel-toe & 3 & 3 \\
\hline Heel-toe & 4 & 4 \\
\hline \multicolumn{3}{|l|}{ Change } \\
\hline Worse & -1 & -1 \\
\hline None & 0 & 0 \\
\hline Better & 1 & 1 \\
\hline
\end{tabular}

All outcome measures were performed blindly by the same physiatrist before and after treatment, and the randomization was applied before the evaluation of the patients.

\section{Treatment program}

All patients received one hour of standard rehabilitation program 5 days a week, for 4 weeks. Standard treatment included range of motion, stretching, balance, and neurophysiologic exercises, resistance and gait training, and occupational therapy. This study reported results using the gait- or mobility-related outcome measures.

FES lower extremity cycle ergometry was accomplished using a motorized cycle-ergometer (MOTOmed VIVA2 Reck (®). Patients were seated on a chair in front of the cycleergometer during treatment (Figure 1).

A current-controlled eight-channel stimulator (Operation Manual RehaStim 2, RehaMove 2, Version 1,2 /2011-09 HASOMED $\left.{ }^{\circledR} \mathrm{GmbH}\right)$ was used, and surface electrodes were applied in a bipolar configuration on both sides of the 
Table 2: Comparison of measurements before and after the treatment in the FES group

\begin{tabular}{|c|c|c|c|}
\hline \multicolumn{4}{|c|}{ FES GROUP $(n=9) M \pm S D$} \\
\hline Parameters & Pre-Treatment & Post-Treatment & $P$ \\
\hline GMFM-88 & $186,44 \pm 32,08$ & $190,77 \pm 33,2$ & $0,001^{*}$ \\
\hline WeeFIM & $73,80 \pm 17,43$ & $74,50 \pm 17,65$ & $0,004^{*}$ \\
\hline 6 minute walk test & $117,83 \pm 86,2$ & $148,72 \pm 106,5$ & $0,001^{*}$ \\
\hline Visual gait analysis & $4,88 \pm 1,05$ & $9,44 \pm 1,66$ & $0,001^{*}$ \\
\hline \multicolumn{4}{|l|}{ Ankle XV1 } \\
\hline Right & $114,44 \pm 11,3$ & $116,66 \pm 7,07$ & 0,129 \\
\hline Left & $115,55 \pm 10,13$ & $117,77 \pm 6,66$ & 0,132 \\
\hline \multicolumn{4}{|l|}{ Ankle XV3 } \\
\hline Right & $87,22 \pm 5,65$ & $100,00 \pm 7,07$ & $0,001^{*}$ \\
\hline Left & $79,33 \pm 26,8$ & $101,66 \pm 7,07$ & $0,001^{*}$ \\
\hline \multicolumn{4}{|l|}{ Ankle MAS } \\
\hline \multicolumn{4}{|l|}{ Right } \\
\hline \multicolumn{4}{|l|}{1} \\
\hline $1+$ & 0 & $2(22,2)$ & $0,013^{*}$ \\
\hline 2 & 0 & $7(77,8)$ & \\
\hline Left & $9(100)$ & 0 & \\
\hline \multicolumn{4}{|l|}{1} \\
\hline $1+$ & 0 & $3(33,3)$ & $0,019^{*}$ \\
\hline \multirow[t]{2}{*}{2} & 0 & $6(66,7)$ & \\
\hline & $9(100)$ & 0 & \\
\hline \multicolumn{4}{|l|}{ Knee XV1 } \\
\hline Right & $166,66 \pm 10,32$ & $175,00 \pm 5,47$ & $0,032^{*}$ \\
\hline Left & $168,33 \pm 7,52$ & $173,33 \pm 8,16$ & 0,203 \\
\hline \multicolumn{4}{|l|}{ Knee XV3 } \\
\hline Right & $148,33 \pm 16,02$ & $160,00 \pm 10,95$ & $0,013^{*}$ \\
\hline Left & $148,33 \pm 14,70$ & $160,00 \pm 10,95$ & $0,012^{*}$ \\
\hline \multicolumn{4}{|l|}{ Knee MAS } \\
\hline \multicolumn{4}{|l|}{ Right } \\
\hline \multicolumn{4}{|l|}{0} \\
\hline 1 & $3(33,3)$ & $3(33,3)$ & 0,171 \\
\hline $1+$ & 0 & $1(11,2)$ & \\
\hline 2 & 0 & $3(33,3)$ & \\
\hline 3 & $5(55,5)$ & $2(22,2)$ & \\
\hline Left & $1(11,2)$ & 0 & \\
\hline \multicolumn{4}{|l|}{0} \\
\hline 1 & $4(44,4)$ & $4(44,4)$ & 0,218 \\
\hline $1+$ & 0 & $1(11,1)$ & \\
\hline 2 & 0 & $3(33,4)$ & \\
\hline \multirow[t]{2}{*}{3} & $4(44,4)$ & $1(11,1)$ & \\
\hline & $1(11,2)$ & 0 & \\
\hline Adductor XV1 & $37,25 \pm 4,99$ & $45,75 \pm 5,43$ & $0,010^{*}$ \\
\hline Adductor XV3 & $27,75 \pm 4,78$ & $41,25 \pm 4,78$ & $0,002^{*}$ \\
\hline \multicolumn{4}{|l|}{ SMC } \\
\hline Right & $2,77 \pm 0,97$ & $2,77 \pm 0,97$ & 1,000 \\
\hline Left & $2,55 \pm 1,13$ & $2,77 \pm 1,97$ & 0,431 \\
\hline
\end{tabular}

${ }^{\star}$ Difference between pre- and post-treatment is significant $(\mathrm{p}<0.05)$

T-test was used for comparison of preand post-treatment continuous measures within the group. A sign test was used for ordinal variables. $\mathrm{M} \pm$ SD:Means,Standard Deviations, FES: Functional electric stimulation, GMFM -88: Gross Motor Function Measure-88, WeeFim: Functional i $n d$ e $p$ e $n d$ e $n c e$ Measure for Children, M A S : M od if i e d Ashworth scale, SMK:selective motor control, XV1:as slow as possible, slower than the rate of natural drop of the limb segment under gravity, XV3:as fast as possible, faster than the rate of natural drop of the limb segment under gravity 
Table 3: Comparison of measurements before and after the treatment in the SHAM group

\begin{tabular}{|c|c|c|c|}
\hline \multicolumn{4}{|c|}{ SHAM GROUP $(n=9), M \pm S D$} \\
\hline Parameters & Pre-Treatment & Post-Treatment & $\mathrm{P}$ \\
\hline GMFM-88 & $197,44 \pm 40,3$ & $201,22 \pm 40,68$ & $0,003^{*}$ \\
\hline WeeFIM & $85,17 \pm 19,58$ & $86,44 \pm 19,61$ & $0,044^{*}$ \\
\hline 6 minute walk test & $168,55 \pm 80,92$ & $217,11 \pm 92,50$ & $0,001^{*}$ \\
\hline Visual gait analysis & $6,22 \pm 3,63$ & $9,66 \pm 3,00$ & $0,007^{*}$ \\
\hline \multicolumn{4}{|l|}{ Ankle XV1 } \\
\hline Right & $114,44 \pm 8,8$ & $116,66 \pm 7,07$ & 0,106 \\
\hline Left & $116,66 \pm 7,07$ & $118,88 \pm 3,33$ & 0,284 \\
\hline \multicolumn{4}{|l|}{ Ankle XV3 } \\
\hline Right & $90,00 \pm 8,66$ & $101.11 \pm 9,61$ & $0,006^{*}$ \\
\hline Left & $89,44 \pm 7,26$ & $102.77 \pm 7,54$ & $0,005^{*}$ \\
\hline \multicolumn{4}{|l|}{ Ankle MAS } \\
\hline \multicolumn{4}{|l|}{ Right } \\
\hline 1 & 0 & $4(44,4)$ & \\
\hline $1+$ & $3(33,3)$ & $4(44,4)$ & $0,041^{*}$ \\
\hline 2 & $6(66,7)$ & $1(11,1)$ & \\
\hline \multicolumn{4}{|l|}{ Left } \\
\hline 1 & 0 & $4(44,4)$ & 0,082 \\
\hline $1+$ & $2(22,2)$ & $5(55,6)$ & \\
\hline 2 & $7(77,8)$ & 0 & \\
\hline \multicolumn{4}{|l|}{ Knee XV1 } \\
\hline Right & $165,00 \pm 8,36$ & $176,60 \pm 5,16$ & $0,023^{*}$ \\
\hline Left & $168,33 \pm 7,52$ & $176,66 \pm 5,16$ & $0,027^{*}$ \\
\hline \multicolumn{4}{|l|}{ Knee XV3 } \\
\hline Right & $148,33 \pm 11,69$ & $160,00 \pm 8,94$ & $0,015^{*}$ \\
\hline Left & $156,66 \pm 13,66$ & $165,00 \pm 10,48$ & $0,026^{*}$ \\
\hline \multicolumn{4}{|l|}{ Knee MAS } \\
\hline \multicolumn{4}{|l|}{ Right } \\
\hline \multicolumn{4}{|l|}{0} \\
\hline 1 & $3(33,3)$ & $3(33,3)$ & \\
\hline $1+$ & 0 & $1(11,1)$ & 0,111 \\
\hline 2 & 0 & $4(44,5)$ & \\
\hline 3 & $5(55,6)$ & $1(11,1)$ & \\
\hline Left & $1(11,1)$ & 0 & \\
\hline \multicolumn{4}{|l|}{0} \\
\hline 1 & $4(44,4)$ & $4(44,4)$ & \\
\hline $1+$ & 0 & 0 & $0,017^{*}$ \\
\hline 2 & 0 & $5(55,6)$ & \\
\hline \multirow[t]{2}{*}{3} & $5(55,6)$ & 0 & \\
\hline & 0 & 0 & \\
\hline Adductor XV1 & $31,75 \pm 3,40$ & $39,25 \pm 2,50$ & 0,256 \\
\hline Adductor XV3 & $21,00 \pm 1,41$ & $35,50 \pm 0,70$ & 0,069 \\
\hline \multicolumn{4}{|l|}{ SMC } \\
\hline Right & $2,62 \pm 0,95$ & $2,62 \pm 0,95$ & 1,000 \\
\hline Left & $2,62 \pm 0,88$ & $2,62 \pm 0,88$ & 1,000 \\
\hline
\end{tabular}

${ }^{\star}$ Difference between pre- and post-treatment is significant $(\mathrm{p}<0.05)$

T-test was used for comparison of pre- and post-treatment continuous measures within the group. A sign test was used for ordinal variables. $\mathrm{M} \pm \mathrm{SD}:$ Means, Standard Deviations, FES: Functional electric stimulation, GMFM -88: Gross Motor Function Measure-88, WeeFim: Functional Independence Measure for Children, MAS:Modified Ashworth scale, SMK:selective motor control, XV1:as slow as possible, slower than the rate of natural drop of the limb segment under gravity ,XV3:as fast as possible, faster than the rate of natural drop of the $\operatorname{limb}$ segment under gravity 
Table 4: Comparison of measurements before and after the treatment in the control group

\begin{tabular}{|c|c|c|c|}
\hline \multicolumn{4}{|c|}{ CONTROL GROUP $(n=7) n(\%), M \pm S D$} \\
\hline Parameters & Pre-Treatment & Post-Treatment & $\mathrm{P}$ \\
\hline GMFM-88 & $206,85 \pm 28,03$ & $211,85 \pm 25,62$ & $0,019^{*}$ \\
\hline WeeFIM & $81,00 \pm 19,75$ & $81,71 \pm 19,63$ & $0,044^{*}$ \\
\hline 6 minute walk test & $184,78 \pm 133,01$ & $209,00 \pm 129,84$ & $0,025^{*}$ \\
\hline Visual gait analysis & $4,28 \pm 1,38$ & $9,00 \pm 2,00$ & $0,016^{*}$ \\
\hline \multicolumn{4}{|l|}{ Ankle XV1 } \\
\hline Right & $108,57 \pm 8,99$ & $115,71 \pm 5,34$ & $0,032^{*}$ \\
\hline Left & $105,71 \pm 11,33$ & $112,85 \pm 7,55$ & $0,036^{*}$ \\
\hline \multicolumn{4}{|l|}{ Ankle XV3 } \\
\hline Right & $84,28 \pm 5,34$ & $95,00 \pm 5,00$ & $0,018^{*}$ \\
\hline Left & $85,00 \pm 8,66$ & $95,71 \pm 7,86$ & $0,014^{*}$ \\
\hline \multicolumn{4}{|l|}{ Ankle MAS } \\
\hline \multicolumn{4}{|l|}{ Right } \\
\hline 1 & 0 & $1(14,3)$ & \\
\hline $1+$ & $1(14,3)$ & $6(85,7)$ & 0,069 \\
\hline 2 & $6(85,7)$ & 0 & \\
\hline \multicolumn{4}{|l|}{ Left } \\
\hline 1 & $1(14,3)$ & $1(14,3)$ & $0,008^{*}$ \\
\hline $1+$ & 0 & $6(85,7)$ & \\
\hline 2 & $6(85,7)$ & 0 & \\
\hline \multicolumn{4}{|l|}{ Knee XV1 } \\
\hline Right & $174,00 \pm 8,94$ & $176,00 \pm 5,47$ & 0,334 \\
\hline Left & $174,00 \pm 8,94$ & $176,00 \pm 5,74$ & 0,338 \\
\hline \multicolumn{4}{|l|}{ Knee XV3 } \\
\hline Right & $150,00 \pm 0,00$ & $162,00 \pm 8,36$ & $0,024^{*}$ \\
\hline Left & $150,00 \pm 0,57$ & $162,00 \pm 4,47$ & $0,032^{*}$ \\
\hline \multicolumn{4}{|l|}{ Knee MAS } \\
\hline \multicolumn{4}{|l|}{ Right } \\
\hline \multicolumn{4}{|l|}{0} \\
\hline 1 & $3(42,9)$ & $3(42,9)$ & \\
\hline $1+$ & 0 & 0 & 0,153 \\
\hline 2 & 0 & $3(42,9)$ & \\
\hline 3 & $3(42,9)$ & $1(14,2)$ & \\
\hline Left & $1(14,2)$ & 0 & \\
\hline \multicolumn{4}{|l|}{0} \\
\hline 1 & $3(42,9)$ & $3(42,9)$ & \\
\hline $1+$ & 0 & 0 & $0,033^{*}$ \\
\hline 2 & 0 & $4(57,1)$ & \\
\hline \multirow[t]{2}{*}{3} & $4(57,1)$ & 0 & \\
\hline & 0 & 0 & \\
\hline Adductor XV1 & $41.00 \pm 5,65$ & $47,50 \pm 3,50$ & 0,215 \\
\hline Adductor XV3 & $30.50 \pm 6,36$ & $41,50 \pm 4,94$ & 0,102 \\
\hline \multicolumn{4}{|l|}{ SMC } \\
\hline Right & $3,00 \pm 0,57$ & $3,00 \pm 0,57$ & 1,000 \\
\hline Left & $3,00 \pm 0,57$ & $3,00 \pm 0,57$ & 1,000 \\
\hline
\end{tabular}

${ }^{*}$ Difference between pre- and post-treatment is significant $(\mathrm{p}<0.05)$

T-test was used for comparison of pre- and post-treatment continuous measures within the group. A sign test was used for ordinal variables. $\mathrm{M} \pm \mathrm{S} D: \mathrm{M}$ e a n s, St a nd ard Deviations, FES: Functional electric stimulation, GMFM -88: Gross Motor Function Measure-88, WeeFim: Functional Independence Measure for Children, MAS:Modified Ashworth scale, SMK:selective motor control, XV1:as slow as possible, slower than the rate of natural drop of the limb segment under gravity ,XV3:as fast as possible, faster than the rate of natural drop of the limb segment under gravity 
Table 5: Distribution and comparison of changes with treatment among the groups by using ANOVA

\begin{tabular}{|l|c|}
\hline Parameters & P \\
\hline GMFM-88 & 0.496 \\
\hline WeeFIM & 0.421 \\
\hline 6 minute walk test & 0.084 \\
\hline Visual gait analysis & 0.073 \\
\hline Ankle XV1 & \\
Right & 0.644 \\
Left & 0.384 \\
\hline Ankle XV3 & \\
Right & 0.099 \\
Left & 0.128 \\
\hline Knee XV1 & \\
Right & 0.197 \\
Left & 0.869 \\
\hline Knee XV3 & \\
Right & 0.950 \\
Left & 0.545 \\
\hline Adductor XV1 & 0.407 \\
\hline Adductor XV3 & 0.791 \\
\hline
\end{tabular}

quadriceps, hamstring, tibialis anterior, and gastrocnemius muscles with an algorithm inducing bilateral reciprocal leg cycling, at between 20-30 revolutions per minute (rpm). The size of the electrodes $(9 \times 5 \mathrm{~cm}$ or $5 \times 5 \mathrm{~cm})$ were chosen according to the weight of the patients and the area of the selected muscles. Rectangular biphasic pulses with a pulse width of $250-300 \mu \mathrm{s}$, the stimulus intensity up to a maximum of $100 \mathrm{~mA}$, and a frequency ranged from 30 to 45 $\mathrm{Hz}$, stimulation phase: 7 seconds, ramp up: 2 seconds, ramp down: 2 seconds were adopted. A pilot FES cycling test was conducted for at least one minute to determine whether participants fulfilled the FES cycle and to determine the program to be applied throughout the therapy. All sessions consisted of a 5-min warm-up of passive cycling, a 20-min training of FES-cycling, and a 5-min cool-down of passive cycling. The patients received instructions from the same physiatrist. The patients were required not to participate voluntarily in the leg pedaling but to keep concentrating on the exercise.

All details were applied to the sham stimulus FES-cycling group in the same way but no stimulus was performed. Either FES-cycling or sham stimulus FES-cycling program was an additional 30 minutes program that was added to the standard treatment for 4 weeks, 5 times/week.

\section{Statistical Analysis}

Data analysis was done by SPSS for Windows 15.0 packet program. Evaluation of the variables for normal distribution was performed by Shapiro-Wilk Test and equal variance assumption was evaluated using Levene's test. According to Levene's test results, we used the data results associated with the "Equal variances assumed". In descriptive statistics, the data were expressed as mean \pm standard deviation for continuous variables (GMFM, WeeFIM, 6-minute walk test, visual gait analysis, MTS XV1 and XV3 as well as SMC), and as frequencies and percentages (\%) for nominal variables (MAS). Two- way ANOVA was used to evaluate if there was a statistically significant difference between pre- and post-therapy within groups as well as the importance of differences among the groups was assessed by ANOVA (bonferroni correction) test for continuous variables. Results were accepted as statistically significant if $\mathrm{p}<0.05$. For our study no samples were calculated but Post-hoc power analysis was made. The data which forms the main hypothesis of the study made up more than $80 \%$ of the operating power in the power analyses and were found sufficient, while for some variables the operating power stayed below the intended level and was considered as a limitation for our study.

\section{Results}

Twenty-five patients with CP with bilateral lower limb involvement were included in the study. Eleven (44\%) were girls and $14(56 \%)$ were boys. Their ages were between 4 to 11 years and the mean age was $6.0 \pm 1.7$ years. No statistically significant difference in age $(p=0.835)$ or gender $(p=0.666)$ was found among the groups.

Of the 25 patients, 16 were able to ambulate with support while 9 were ambulatory without support. No significant difference was found among groups concerning ambulation $(p=0.376)$ and GMFCS system levels $(p=0.392)$.

Outcome measures of pre- and post-treatment results for groups were presented in Tables 2-4.

There was no difference for bilateral knee and ankle MAS changes after treatment evaluated by Sign test (right knee $\mathrm{p}=0.350$, left knee $\mathrm{p}=0.491$, right ankle $\mathrm{p}=0.165$, left ankle $\mathrm{p}=0.350)$.

No statistically significant difference was obtained in terms of changes in other parameters after treatment among groups ( $\mathrm{p}>0.05)$ (Table 5).

There weren't any FES-cycling related side effects. The intensity levels of FES stimulation were well tolerated. The parents were willing to continue the study.

\section{Discussion}

The clinical picture in CP may change in time due to the growth of the child and other factors. Botulinum toxin type-A injections which are used commonly in spasticity treatment, recently are applied as a helpful complementary treatment among conventional methods $\stackrel{22,23}{2}$. In addition to this, it should not be used alone but should be combined with conventional therapies and surgical methods $\stackrel{24,25}{2}$. However, there is insufficient evidence to ascertain which combination or alternative therapy would be the most useful in treating spasticity 26. FES cycling programs have been reported to provide significant physical benefits including increased muscle size, reduced contractures, and spasticity, improved neurological and functional performance ${ }^{7}$.

The present study aimed to evaluate the effects of FEScycling in patients with spastic diplegic CP who had undergone treatment with Botulinum toxin type A. FES was applied to bilateral quadriceps, hamstring, tibialis anterior and gastrocnemius muscles in this study. In the literature, the effects of the botulinum toxin injection and FEScycling therapy were evaluated separately in children with cerebral palsy ${ }^{27,28}$. In our study, after the botulinum toxin injection, patients were divided into 3 groups and included in 
a rehabilitation program in three different protocols lasting 4 weeks. Post-injection rehabilitation is an integral part of the treatment. Although botulinum toxin administration is an effective treatment method for the reduction of spasticity in patients with cerebral palsy, it is not a single treatment method, it should be considered as a part of the rehabilitation program. The reduction of spasticity after injection provides patients with a therapeutic window. The purpose of physiotherapy after the application is to maintain musculoskeletal system biomechanics and range of motion, to improve muscle strength and endurance, to provide a balance between agonist and antagonist muscles, and to provide proprioceptive training $3,29,30$.

\section{Motor Function}

In our study, there was no significant difference regarding the GMFCS levels before and after treatment among groups.

All patients included in the study were able to ambulate (supported or unsupported) and their GMFM-88 levels were considerably high. While there were statistically significant differences between pre- and post-treatment values of GMFM-88 levels for all groups, no significant difference among groups at the end of 4 weeks was found. Responsiveness of the GMFM- 88 has been shown on a 2-month follow-up study comparing the effect of the aerobic, anaerobic, and strengthening exercises $\frac{31}{}$. The short term rehabilitation period in our study might show that GMFM-88 levels do not differ among groups.

\section{6-Minute Walk Test}

A 6-minute walk test, a simple, sub-maximal exercise test, was used to evaluate cardiopulmonary fitness

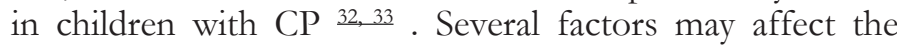
results of the test. Walking capacity may be reduced due to spasticity, impaired balance, and decreased muscle strength ${ }^{34,35}$. Balbaloglu et al. evaluated the walking speed and walking distance with a 6-minute walk test after application of multilevel botulinum toxin injection to lower limbs of children with hemiplegic and diplegic $\mathrm{CP}$ and demonstrated significant improvements in all parameters $\frac{36}{}$. In our study, after the treatment, 6-minute walking distance increased in all groups, but these values did not reach statistically significant levels among the groups. Unlike the standard treatment group, the 2 groups who applied cycling performed aerobic exercise, we expected a significant change in the 6-minute walking test in these groups, but the small number of patients may have caused no significant difference.

\section{Visual Gait Analysis}

Visual Gait analysis was used to evaluate the gait characteristics of the patients. Statistically, significant amelioration was seen in the walking patterns such as an increase in ankle dorsiflexion, an improvement in foot contact, in all groups after the treatment but no difference was observed among the groups. In a recent study, Galen et al. applied FES to tibialis anterior muscle following botulinum toxin injections to gastrocnemius muscle to evaluate gait patterns in children with CP. They found an increase in ankle dorsiflexion at the end of the combined intervention in most subjects, accompanied by an improvement in foot contact pattern 37 .

\section{Spasticity}

MAS and MTS were used to evaluate the effects of applied treatments on spasticity. In a study with 19 diplegic and 4 hemiplegic patients, Hesse et al. stated that even after 4 weeks of botulinum toxin injection, patients could show more plantigrade foot posture and upright posture $\frac{38}{2}$. In a study by Dincer et al, patients were rehabilitated following botulinum toxin injections, and the spasticity was evaluated with MAS and joint range of motion, and walking patterns were evaluated by physician observation. They recorded statistically significant improvements in all parameters 39 In our study, there was a significant improvement in the bilateral ankle MAS level in the FES-cycling group after treatment. The other two groups presented improvements in bilateral ankle MAS levels, but this was statistically significant only on one side. But there was no statistically significant difference among groups. Moreover, there was a statistically significant difference in XV3 levels of 3 groups after treatment considering ankle MTS within the groups. On the other hand, there was no statistically significant difference in XV3 measurements of 3 groups after treatment among the groups. Furthermore, adductor spasticity was evaluated by measuring the distance between knees (XV1, XV3). There was a statistically significant increase only in the FEScycling group after treatment. Sham and standard treatment groups showed clinical progress but it was not statistically significant. Mall et al. were also reported a significant increase in the distance between knees and a significant decrease in adductor spasticity following botulinum toxin injections to adductor and medial hamstring muscles ${ }^{40}$.

\section{Selective Motor Control}

Selective motor control examination was performed to evaluate insufficiency in selective ankle dorsiflexion that affects the ambulation ability and functional gait pattern. SMC are significant factors that limit gross motor function in ambulant individuals with bilateral spastic CP. ${ }^{41}$

After treatment, 2 children in the FES-cycling group showed one degree of progress even it was not statistically significant and no difference was found in other groups.

\section{Functional Independence and Daily Living Activities}

WeeFIM is proved to be a safe and valid measure for children between 6 months to 12 years old ${ }^{13,42}$. In our study, statistically significant improvements were observed in WeeFIM scores of all 3 groups after the rehabilitation period, but there was no statistically significant difference among groups. Larger scale studies with longer follow-up are needed to determine the true impact of these methods.

The limitations of our study were relatively small sample size, and short study period because of the presence of excessive exclusion criteria which might lead to exclusion of a large proportion of patients. In the study, it was not sufficient to have the diagnosis of cerebral palsy, it was also required to meet the criteria for FES application. Since there is no relevant prevalence data in the literature, the study was planned as "hospitalized patients within 1 year."

In conclusion, all groups showed statistically significant improvements in motor function, walking pattern, spasticity, daily living activities, and aerobic capacity in patients with CP following the rehabilitation period. Although FES-cycling demonstrated no superiority over the other approaches and provided no additional benefit to the results, FES appears to be safe and well-tolerated in children with $\mathrm{CP}$, at least as much as standard exercise treatment, studies with larger sample sizes and longer intervention times are needed to reveal accurate evidence and time and cost-effectiveness 
before recommending the intervention.

\section{Conflict of interest}

The authors declared no potential conflicts of interest with respect to the research, authorship, and/or publication of this article.

\section{Compliance with Ethical Standards}

Ethical approval: All procedures performed in studies involving human participants were in accordance with the ethical standards of the institutional and/or national research committee and with the 1964 Helsinki declaration and its later amendments or comparable ethical standards.

Subjects were informed about the study and their written informed consents were obtained at the beginning of the study.

\section{Funding}

The authors disclose; did not receipt financial support for the research, authorship, and/or publication of this article.

\section{References}

1. Rosenbaum P, Paneth N, Leviton A, Goldstein M, Bax M, Damiano $\mathrm{D}$ et al. A report: the definition and classification of cerebral palsy. Dev Med Child Neurol. 2007; 49(6): 480.

2. Balaban B, Yaşar E, Dal U Yazicioglu K. The effect of functional level on energy metabolism in children with cerebral palsy. Turk J Phys Med Rehab. 2006; 52(1): 11-14.

3. Balbaloglu O, Basaran A, Ayoglu H. Functional outcomes of multilevel botulinum toxin and comprehensive rehabilitation in cerebral palsy. J Child Neurol. 2011; 64(1): 482-487.

4. Schlough K, Nawoczenski D, Case LE, Nolan K, Wigglesworth JK. The effects of aerobic exercise on endurance, strength, function and sefperception in adolescents with spastic cerebral palsy: a report of three case studies. Pediatr Phys Ther. 2005; 17(4): 234-250.

5. Verschuren O, Ketelaar M, Gorter JW, Helders PJ, Uiterwaal CS, Takken T. Exercise Training Program in Children And Adolescents With Cerebral Palsy. Arch Pediatr Adolesc Med. 2007; 161(11): 10751081.

6. Dursun N. Serebral Palsi (Cerebral palsy). In: Oğuz H, Dursun E, Dursun, editors. Tibbi Rehabilitasyon. 1st ed. İstanbul: Nobel Tip Kitapevleri, 2004, p. 957-974

7. Sadowsky CL, Hammond ER, Strohl AB, Commean PK, Eby SA, Damiano DL, Wingert JR, Bae KT, McDonald JW 3rd. Lower extremity functional electrical stimulation cycling promotes physical and functional recovery in chronic spinal cord injury. J Spin Cord Med. 2013;36(1): 623-31.

8. Armstrong EL, Boyd RN, Horan SA, Kentish MJ, Ware RS, Carty CP. Functional electrical stimulation cycling, goal-directed training, and adapted cycling for children with cerebral palsy: a randomized controlled trial. Dev Med Child Neurol. 2020;62(12):1406-1413.

9. Trevisi E, Gualdi S, De Conti C, Salghetti A, Martinuzzi A, Pedrocchi A, Ferrante S. Cycling induced by functional electrical stimulation in children affected by cerebral palsy: case report. Eur J Phys Rehabil Med. 2012;48(1):135-45.

10. Harrington AT, McRae CG, Lee SC. Evaluation of functional electrical stimulation to assist cycling in four adolescents with spastic cerebral palsy. Int J Pediatr. 2012;2012:504387.

11. World Medical Association Declaration of Helsinki: ethical principles for medical research involving human subjects. JAMA. 2013; 310(20): 2191-2194.

12. Viera AJ, Bangdiwala ST. Eliminating Bias in Randomized Controlled Trials: Importance of Allocation Concealment and Masking. Fam Med. 2007; 39(2): 132-137.
13. Boyd RN, Graham HK. Objective measurement of clinical findings in the use of botulinum toxin type A for the management of children with cerebral palsy. Eur J Neurol 1999; 6(1): 23-35.

14. Yam WKL, Leung MSM. Interrater reliability of modified Ashworth scale and modified Tardieu scale in children with spastic cerebral plasy. J Child Neurol. 2006; 21(1): 1031-1035.

15. Erkin G, Aybay C. Functional Assessment Methods Used in Pediatric Rehabilitation. Turk J Phys Med Rehab. 2001; 47(1); 16-26.

16. Russell, P. Rosenbaum, M.Avery. Gross Motor Function Measure (GMFM-66\&GMFM-88) User's Manual; Cambridge Un. Press, 2002, p. 1-24.

17. Berweck S, Heinen F. Blue Book Botulinum toxin, Treatment Of Cerebral Palsy With Botulinum Toxin Principles, Clinical Practice. 1st ed. Child And Brain GMBH, Bonn, 2003, p. 57-82.

18. James S, Ziviani J, Boyd R. A systematic review of activities of daily living measures for children and adolescents with cerebral palsy. Dev Med Child Neurol. 2014 Mar;56(3):233-44

19. Maathuis KG, van der Schans CP, van Iperen A. Gait in children with cerebral palsy: observer reliability of Physician Rating Scale and Edinburgh Visual Gait Analysis Interval Testing scale. J Pediatr Orthop. 2005; 25(1): 268-272.

20. Verschuren O, Bloemen M, Kruitwagen C, Takken T. Reference values for aerobic fitness in children, adolescents, and young adults who have cerebral palsy and are ambulatory. Phys Ther. 2010 Aug;90(8):1148-56.

21. Fitzgerald, Diarmaid PT, PhD; Hickey, Claire PT, BSc; Delahunt, Eamonn PT, PhD, et al. Six-Minute Walk Test in Children With Spastic Cerebral Palsy and Children Developing Typically.Pediatric Physical Therapy: 2016 ; 28(2): 192-199.

22. Im D, McDonald CM . New approaches to managing spasticity in children with cerebral palsy. West J Med. 1997; 166(1): 271.

23. Heinen F, Molenaers G, Fairhurst C, Carr LJ, Desloovere K, Chaleat Valayer E, et al. European consensus table 2006 on botulinum toxin for children with cerebral palsy. Eur J Paediatr Neurol. 2006; 10(5-6): 215-225.

24. Lowe K, Novak I, Cusick A. Low-dose/high-concentration localized botulinum toxin A improves upper limb movement and function in children with hemiplegic cerebral palsy. Dev Med Child Neurol. 2006; 48(1): 170-175.

25. Hägglund G, Andersson S, Düppe H, Lauge-Pedersen H, Nordmark E, Westbom L. Prevention of severe contractures might replace multilevel surgery in cerebral palsy: results of a population-based health care programme and new techniques to reduce spasticity. J Pediatr Orthop B. 2005; 14 (5): 269-273.

26. Lannin N, Scheinberg A, Clark K. AACPDM systematic review of the effectiveness of therapy for children with cerebral palsy after botulinum toxin A injections. Dev Med Child Neurol. 2006; 48(1): 533539.

27. Van der Linden ML, Hazlewood ME, Hillman SJ, Robb JE. Functional electrical stimulation to the dorsi flexors and quadriceps in children with cerebral palsy. Pediatr Phys Ther. 2008; 20(1): 23-29.

28. Seifart A, Unger M, Burger M. Functional electrical stimulation to lower limb muscles after botox in children with cerebral palsy. Pediatr Phys Ther. 2010; 22(1): 199-206.

29. Wiley ME, Damiano DL. Lower-extremity strength profiles in spastic cerebral palsy. Dev Med Child Neurol. 1998; 40(1): 100-107.

30. Matthews DJ, Wilson P. Cerebral Palsy. In: Molnar GE, Alexander MA, editors. Pediatric Rehabilitation, 3rd ed. Philadelphia: Hanley and Belfus Inc. 1999, p. 193-219.

31. Verschuren O, Ketelaar M, Gorter JW, Helders PJ, Uiterwaal CS, 
Takken T. Exercise Training Program in Children And Adolescents With Cerebral Palsy. Arch Pediatr Adolesc Med. 2007; 161(11): 10751081.

32. Guyatt GH, Sullivan MJ, Thompson PJ, Fallen EL, Pugsley SO, Taylor DW et al. The 6-minute walk: a new measure of exercise capacity in patients with chronic heart failure. Can Med Assoc J. 1985; 132 (8): 919-923.

33. Buffart LM, van den Berg-Emons RJ, van Mechelen W, van Meeteren J, van der Slot W, Stam HJ et al. Promoting physical activity in an adolescent and a young adult with physical disabilities. Disabil Health J. 2010; 3(2): 86-92.

34. Hanson CJ, Jones LJ. Gait abnormalities and inhibitive casts in cerebral palsy. Literature review. J Am Podiatr Med Assoc. 1989; 79 (1): 53-59.

35. Norlin R, Odenrick P. Development of gait in spastic children with cerebral palsy. J Pediatr Orthop. 1986; 6(1): 674-680.

36. Balbaloglu O, Basaran A, Ayoglu H. Functional outcomes of multilevel botulinum toxin and comprehensive rehabilitation in cerebral palsy. J Child Neurol. 2011; 64(1): 482-487.

37. Galen S, Wiggins L, McWilliam R, Granat M. Combination of Botulinum Toxin A therapyand Functional Electrical Stimulation in children with cerebral palsy--a pilot study. Technol Health Care. 2012; 20(1): $1-9$.
38. Mehrholz J, Wagner K, Meissner D, Grundmann K, Zange C, Koch $\mathrm{R}$ et al. Reliability of the Modified Tardieu Scale and the Modified Ashworth Scale in adult patients with severe brain injury: a comparison study. Clin Rehabil. 2005; 19(7): 751-759.

39. Dinçer U, Çakar E, Kıralp MZ. Comparison of efficacy of physiotherapy and lower extremity orthosis after botulinum toxin administration in patients with diplegic cerebral palsy. Turk J Phys Med Rehab. 2008; 54(1): 41-45.

40. Mall V, Heinen F, Siebel A Bertram C, Hafkemeyer U, Wissel J et al. Treatment of adductor spasticity with BTX-A in children with CP: a randomized, double-blind, placebo-controlled study. Dev Med Child Neurol. 2006; 48(1): 10-13.

41. Noble JJ, Gough M, Shortland AP. Selective motor control and gross motor function in bilateral spastic cerebral palsy. Dev Med Child Neurol. 2019 Jan;61(1):57-61.

42. Tur BS, Küçükdeveci AA, Kutlay S Yavuzer G, Elhan AH, Tennant A. Psychometric Properties of The WeeFIM in Children with Cerebral Palsy in Turkey. Dev Med Child Neurol. 2009; 51(9): 732-738. 